general averages vary from area to area, but show, on the whole, a close similarity to those obtained by Roberts and by the Anthropometric Committee for the artisan classes some forty years back, though in this volume there are not enough data to enable the different areas to be contrasted on an ethnographic basis.
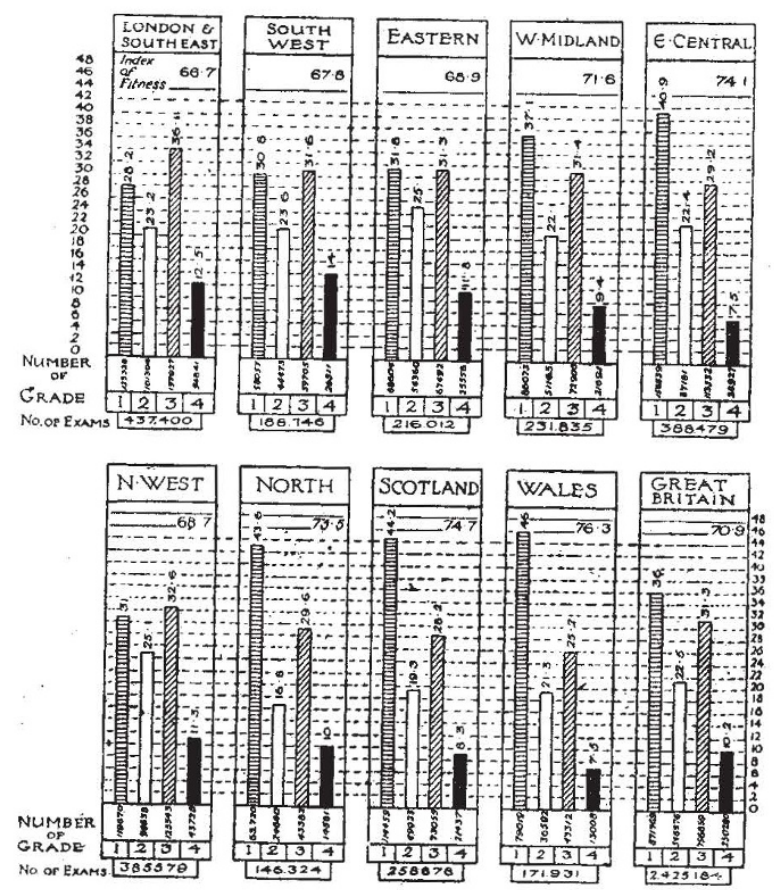

FIG. 1.-Graphical representation of physical fitness in each region of Great Britain. The diagrams show for each region the actual numbers and percentage for each grade, as well as the index of fitness. They provide, therefore, a convenient means of comparing the relative physical condition of the respective populations.

Physique and general fitness fall off with advancing years, and it is noted from several areas that after the age of fifty practically no recruits of military value are to be obtained. One Commissioner generalises the observations by pointing out that while the physical standard of early manhood was determined by inheritance modified by environment, above the age of forty, the determining factor was how a man had lived his earlier life.

The variation in physique with different occupations is very marked, as can be seen from the respective indices of fitness of groups, though it would perhaps be well to defer detailed comparison until full figures are available. The following may serve as illustrations

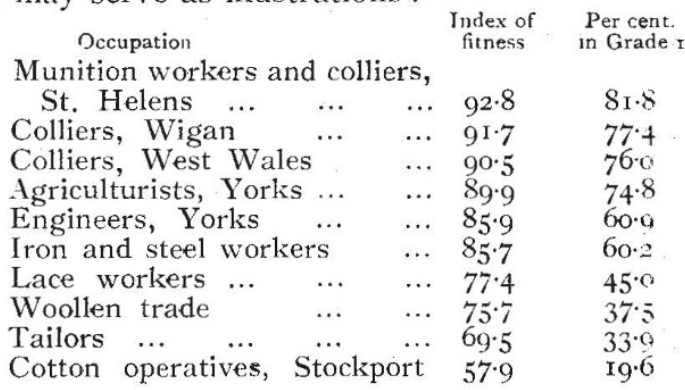

This is also seen by comparison of townse.g. in March, 1918, Sheffield showed an index of 83.3 with 61 per cent. in Grade $I$, and Leeds an index of 62 with 14.5 per cent. in Grade $r$. It is evident that the men of good physique are found in the heavier occupations. Among the causes of low grading, heart disease and tuberculosis take a high place, while in some areas there is a prevalence of infantile paralysis. Contrary to expectations raised by the recent campaign on public morals, the incidence of venereal disease as a cause of low grading is nearly negligible. A special series of charts shows the full data obtained as to the relation between occupation grading and disease in the London area. Sedentary occupations show the worst results, and it is a question whether in part it is not as much that those of inferior physique gravitate to sedentary work as that this in itself is harmful. Heart and circulatory disease, and to a less extent congenital or acquired deformities, constitute the chief causes of deficiency.

The information available in this volume is such as to require almost a separate description for each section, and the Ministry is to be congratulated on a volume which should be on the shelves of every social worker and reformer.

\title{
The Doctor of Philosophy in England.
}

THE neglect on the part of the English universities in not recognising a special faculty of philosophy has been remarkable, but this singular circumstance is of rare interest to the student of the history of universities. It is a curious fact indeed that the title of doctor itself dates, though with some uncertainty, to the first half of the twelf th century at Bologna, and to the middle of that century at Paris. About a century later the doctorate in law and divinity came into use in England, and in the fourteenth century followed that of medicine. In the fifteenth the English universities took the lead in conferring the degree of doctor of music. Yet doctorates in grammar, logic, and philosophy were given in Germany so early as the thirteenth century. Until comparatively recently the M.A. in England ranked above the Mus.Doc.

To those acquainted with the history and the evolution of degrees, that of master of arts must carry the greatest respect, if not veneration, from the point of view of antiquity, for it conveys with it the first traditions of the spread of learning in Europe, being as it is by far the oldest of degrees. The earliest teachers bore the titles of lord, master, and judge (dominus, magister, judex), which were in common use long before that of doctor. In fact, to this day the German NO. 2633 , VOL. IO5] 
Ph.D. is primarily a master of arts, the degree being properly Magister Artium et Doctor Philosophiae, and is given for research, just as the Cambridge research M.A. is to-day. Whether the Cambridge research student who has already taken his M.A. will be qualified before long to add Ph.D. to his name remains, however, to be seen. Rashdall, in his "Europe in the Middle Agres," ridicules the practice now becoming prevalent in England of giving the master's and doctor's degrees in the same faculty; as, for instance, the LL.M. and LL.D. at Cambridge. Just as a doctor may have been learned in his own faculty, so was the master supposed to be supreme in his. In fact, the terms master, professor, and doctor were in the Middle Ages almost identical; and until Cambridge introduced the anachronism of the LL.M. in the nineteenth century, the master had always been regarded as equivalent to the doctor in his own special faculty. But the fusion of the two in Germany in the Ph.D. was in strict accordance with tradition, and perfectly correct.

It may be recalled that in England in the Middle Ages, as in Paris, teachers of law were styled doctors, and those of theology masters. The doctor of divinity, on the other hand, was a characteristic of Bologna, and the jealousy existing between the universities tended for some time to keep these features distinct.

In recent times, however, the doctorate has assumed a higher rank than the masterate. The University of Yale in 1860 first conferred the degree of Ph.D. after the German style, and this was followed by other universities in the United States. The commercial aspect of the question being of importance, there has been a strong tendency in recent years to recognise the disadvantages imposed upon students of research in this country, as compared with their rivals from Germany and the United States. For some time past-in fact, since 1895 -Cambridge has given a Certificate for Research with the B.A. and M.A.- a distinction which is understood to rank with a first class in Part II. of the Tripos. This certificate testifies the candidate's dissertation to be "a work of importance and distinction as a record of original research." It is about the same standard as the German Ph.D. But the general public, being little acquainted with these innovations, continued to regard the Ph.D. as the hall-mark of respectability for all research workers, even in this country.

During the last year or two, however, Oxford, perceiving the need, has instituted the degree of D.Phil. for the benefit of those $(a)$ who have attained the status of advanced student in the university, by having been placed in the first or second class in the Final Honours School, or in the first class in an Honours School of the First Public Examination, and passed all necessary examinations for the degree of B.A. ; $(b)$ students from other universities who have attained a similar standard, and can produce evidence of fitness to NO. 263.3 , VOL. IO57 engage in research, having pursued a course of study at one or more universities extending over four years at least. After two years at Oxford, such students may, as a rule, apply for the D.Phil. by presenting a dissertation, which must constitute an original contribution to knowledge, set forth in such a manner as to be fit for publication in extenso, being, in the opinion of the examiners, of sufficient merit to qualify for the degree.

The example of Oxford has been followed by Cambridge. A new statute authorising the degree of doctor of philosophy for research has been approved by the Privy Council, and the regulations will be put before the Senate at the first Congregation in the Easter term. The statute will rescind the old regulations relating to research students. As in the case of Oxford, the status of an advanced student, known now at Cambridge as research student, must be attained, whether by graduates of Cambridge or by students from other universities. (a) A student, being a graduate of Cambridge, who has from the time of his admission as a research student pursued in the university, or in some other recognised place of study, a course of research for not less than three years, one year of which has been spent at Cambridge, and two either at Cambridge or at some other recognised place of study, may, not earlier than the ninth, and not later than the twelfth, term from his admission as a research student, submit a dissertation embodying the results of his research. (b) A student who, not being a graduate of the university, has kept by residence not less than six terms in a course of research, and pursued research for not less than three years, two of which have been at Cambridge, and one either at Cambridge or elsewhere recognised by the authorities, may, not earlier than his ninth, and not later than his twelfth, term as a research student, submit a dissertation embodying the results of his research. It is not quite clear whether, and if so what, provisions are made for those research students who have already taken the research M.A. having worked for the prescribed period at Cambridge or elsewhere.

At present a master of arts of five years' standing-that is, twelve years from matriculationmay apply for the Sc.D. The fee varies from twenty-five guineas to nearly $50 l$, according to the college. But very few ever proceed to this, since by the time the necessary status is reached most men consider that they have had sufficient patronage and paid enough for their education to trouble about it. They are usually by that time tired of examinations and of submitting themselves to the criticism of examiners, some of whom, having remained at the university, holding small teaching appointments, may not have attained quite the same status in the outer world.

It is a matter of importance that examiners for such degrees should have the confidence of the candidates, as well as of the university authorities, as being at least their equals, if not superiors, 
in the knowledge of the special subjects of the dissertations; for at some universities professors who have never published anything whatever are asked, as professors, to examine, for the doctorate, candidates with a European reputation! An instance of this nature has recently occurred in one of the universities in this country, the professors being almost unknown outside its walls. But no doubt Oxford and Cambridge may be trusted to stand above rendering such an injustice to those who seek their recognition and come from afar for the benefits they bestow.

\section{British Crop Production. ${ }^{1}$}

\section{By Dr. Edward J. Russell, F.R.S.}

F ODDER and hay crops play a more important part than cereals in the economy of the farm, because they are the raw materials for a highly important part of the farmer's business-the production of meat, milk, or butter. They are too bulky to transport in any quantity, and farmers use only as much as they themselves grow. The output of meat and dairy produce is, therefore, limited by the quantities of these crops at the farmer's disposal. The quantities produced just before the war and in ris 8 were :-

$$
\begin{gathered}
\begin{array}{c}
\text { Production of Fodder and Hay Crops. } \\
\text { Yield per acre } \\
\text { 1908-17 }
\end{array} \text { Millions ol acres }
\end{gathered}
$$

England United $\overbrace{\begin{array}{c}\text { England and } \\ \text { Kand } \\ \text { Wingles }\end{array}}^{\text {United }} \begin{gathered}\begin{array}{c}\text { Total } \\ \text { pruduce. } \\ \text { Kingdom }\end{array} \\ \text { Millions of }\end{gathered}$ Wales dom $\overbrace{\text { tons }}^{\text {Kales }}$

tons tons 1914 1918 1914 1918 $191_{4} \quad 1918$

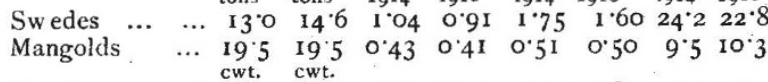

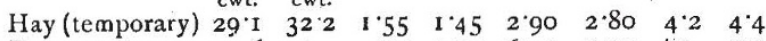
$\begin{array}{lllllllll}\text { Permanent grass } & 22.6 & 279 & 4^{*} 79 & 4^{*} 30 & 6.49 & 5.95 & 8^{\circ} \cdot 2 & 7 \cdot 9\end{array}$

Like cereals and potatoes, these crops are greatly affected by artificial fertilisers, especially by phosphates, which increase not only the yield, but also the feeding value per ton. This is strikingly shown in the case of swedes and turnips, which receive a large part of the superphosphate made in this country. Mangolds respond remarkably well to potassic fertilisers and to salt. There is much to be learned from a systematic study of the influence of artificial manures on the composition and feeding value of these crops under the varied conditions of this country.

A further reason for the important part played by these crops in the economy of the farm is that they profoundly affect the fertility of the soil. They do not remove from the soil all the fertilising constituents which must be added to secure maximum growth; some of these constituents are left behind in the soil to benefit the next crop-a rare instance of double effectiveness for which the farmer ought to be profoundly thankful. In the second place, even the fertilising constituents which are absorbed by the crop are not entirely retained by the animal; considerable quantities are excreted and pass into the manure, and again are added to the soil. There is, therefore, the possibility of constant improvement of the soil ; larger fodder crops enable more livestock to be kept, more livestock make more manure, and more manure gives still larger crops. It is sometimes argued that meat or milk production is in some way opposed to corn production, but on this method there is no antagonism; on the contrary, each helps the other. The production of more meat is consistent with, and indeed involves, the production of more corn.

The simplest way of utilising animal excretions without loss is to allow the animals to consume the crop on the land where it grows, and this is frequently 1 Discourse delivered at the Royal Institution on Friday, February 20. Continued from p. 178 .

$$
\text { NO. } 2633 \text {, VOL. I05] }
$$

done excepting where the soil is so sticky as to become very unpleasant in wet weather. Sheep are the best animals for the purpose, as they are easily penned in by light hurdles, these being moved as each portion of the freld is cleared; this folding is a common occurrence on the chalky and sandy soils of the Southern and Eastern Counties.

Bullocks are less tractable, and cannot be enclosed by light hurdles; they are, therefore, generally kept in yards, roofed in if possible, but oftentimes open. Sufficient straw is added to provide them with bedding and to soak up the excretions. In this wav the fertilising constituents of the straw as well as of the food are returned to the soil.

In the case of dairy cows the treatment is rather different; they have to be housed properly in quarters which are sometimes palatial, and for hygienic reasons they are allowed but little bedding. Their manure is removed once daily-sometimes oftener-the primary object being to get it away without contaminating the milk. The investigations already referred to for which Lord Elveden provides the funds are now being extended to the dairy farm to see how far it is possible to save the manure without prejudice to the purity of the milk.

In the old days, when farmyard manure was the only manure and the old type of implements alone were available, farmers had to arrange their crops on a definite plan in order to get through their work and maintain permanently the productiveness of the land. There thus grew up a system known as the rotation of crops, which contributed very largely to the agricultural developments of the 'sixties, and ultimately became a rigid rule of husbandry strictly enforced over large parts of the country. Modern cultivation implements and fertilisers justify much more latitude, however, and no good farmer ought to be restricted in his cropping, provided, of course, that he maintains the fertility of his land. It is sometimes a convenience on the dairy farm to grow the same crop year after year on the same land, and the Rothamsted experiments show that this can be done, excepting only in the case of clover. With this exception there is no more need to have a rotation of crops than there is to have a rotation of tenants in a house. It is essential, however, that the land should be kept free from other competitors and from disease germs. Freedom from competition means the exclusion of weeds. In the old davs this had to be effected by periodical bare fallows. Nowadays a different course is possible; modern cultivation implements worked by a tractor allow great scope for the suppression of weeds. There is, however, one crop that must be grown periodically to ensure the best results--clover or a mixture of clover and grass. Clover affords valuable food for cattle during winter, and it also enriches the soil in highly valuable nitrogenous organic matter. Much of this is the work of the plant itself, and could equally well be done by grass; but the enrichment in nitrogen is the work of bacteria residing 